\title{
Increase in the Neuraminidase Activity of a Nonpathogenic Newcastle Disease Virus Isolate during Passaging in Chickens
}

\author{
Ryota TSUNEKUNI ${ }^{1,3)}$, Hiroshi ITO ${ }^{1,2)}$, Hiroshi $\mathrm{KIDA}^{4)}$, Koichi OTSUKI ${ }^{3)}$ and Toshihiro ITO ${ }^{1,2) *}$ \\ ${ }^{1)}$ Department of Veterinary Public Health, ${ }^{2)}$ Avian Zoonosis Reseach Center, Faculty of Agriculture, Tottori University, Tottori 680-8553, \\ ${ }^{3)}$ Avian Influenza Research Center, Kyoto Sangyo University, Kamigamo-Motoyama, Kyoto 603-8555 and ${ }^{4)}$ Department of Disease \\ Control, Graduate School of Veterinary Medicine, Hokkaido University, Sapporo 001-0021, Japan
}

(Received 22 October 2009/Accepted 28 November 2009/Published online in J-STAGE 15 December 2009)

\begin{abstract}
A pathogenic mutant of the Newcastle disease virus (NDV) was previously generated by passaging a non-pathogenic isolate from wild waterfowl. Velogenic mutant 9a5b (IVPI=2.67) contains three amino acid substitutions $(128 \mathrm{H}$, 495K and 573stop) in the hemagglutinin-neuraminidase $(\mathrm{HN})$ protein, as compared with nonpathogenic waterfowl isolate $415 / 91$ strain, and two of these (128H and $495 \mathrm{~K}$ ) were introduced after mesogenic $9 \mathrm{a} 3 \mathrm{~b}$ (IVPI=1.88). To investigate the role of the HN protein in NDV virulence, the function of $\mathrm{HN}$ protein such as neuraminidase (NA), Hemadsorption (HAd) and fusion promotion activities was examined by introducing the point mutations observed in passaged mutants into the HN gene cDNAs. In vitro functional assay using mutant protein expression demonstrated that the $128 \mathrm{H}$ substitution markedly increases NA activity and 573stop substitution increase NA and HAd activities. On the other hand, $495 \mathrm{~K}$ substitution had little effect on any activities. These results indicate that a single amino acid substitution (128P to $\mathrm{H})$ in the NDV HN protein affects the neuraminidase activity and is possibly correlated with the virulence.

KEY WORDS: hemagglutinin-neuraminidase protein, IVPI, Newcastle disease virus, passage, pathogenicity.
\end{abstract}

J. Vet. Med. Sci. 72(4): 453-457, 2010

Newcastle disease virus (NDV) is classified as a member of the genus Avulavirus, belonging to the family Paramyxoviridae $[12,16]$. It causes a highly contagious respiratory, neurological or enteric disease in all species of birds, and is responsible for significant economic losses in the commercial poultry industry worldwide. Strains of NDV can be differentiated on the basis in their pathogenicity in chickens into strains of high (velogenic), intermediate (mesogenic) and low (lentogenic) virulence $[1,2,24]$.

NDV has two surface glycoproteins, a fusion (F) protein and a hemagglutinin-neuraminidase $(\mathrm{HN})$ protein [11]. The $\mathrm{F}$ protein mediates fusion of the virion envelope with the cellular plasma membrane. It is synthesized as an inactive precursor, $\mathrm{F}_{0}$, which must be proteolytically cleaved to form a disulfide-linked heterodimer of $\mathrm{F}_{1}$ and $\mathrm{F}_{2}$ in order to activate membrane fusion activity. The $\mathrm{F}$ proteins of virulent strains differ from those of avirulent strains with regard to the presence of a pair of dibasic amino acids at the carboxyl (C) terminus of $F_{2}[5,20,22]$. Whereas the $F$ protein of virulent strains is cleaved by furin or other ubiquitous intracellular host cell proteases, the F protein of avirulent strains is cleaved by trypsin-like enzymes found in limited tissue. As a result, avirulent strains can only replicate in areas with trypsin-like enzymes, such as the respiratory and intestinal tracts, whereas virulent strains can replicate in a range of tissues and organs, resulting in fatal systemic infection [20, 21].

The HN protein possesses both the receptor recognition

\footnotetext{
* Corresponence to: Ito, T., Department of Veterinary Public

Health, Faculty of Agriculture, Tottori University, 4-101

Minami, Koyama-cho, Tottori 680-8553, Japan.
}

e-mail: toshiito@muses.tottori-u.ac.jp and neuraminidase (NA) activities associated with the virus. It is responsible for the attachment of virus particles to sialic acid-containing receptors of the host cell, it promotes the fusion activity of the F protein and acts as NA by removing the sialic acid from progeny virus particles in order to prevent self-agglutination $[10,11,27]$. Thus, the $\mathrm{HN}$ protein plays an important role in viral infection. Chimeric experiments using recombinant viruses with the $\mathrm{HN}$ genes of virulent and avirulent strains demonstrated changes in virulence $[8,14]$. Therefore, the HN protein of NDV is thought to affect pathogenicity in chickens.

In a previous study, we reported the generation of the mesogenic NDV 9a3b and velogenic 9a5b strains [25] from a nonpathogenic waterfowl isolate, Goose/Alaska/415/91 $(415 / 91)$ strain [26], by passaging in chicken air sac and brain. Sequence analysis of the F protein cleavage site showed that the increase in pathogenicity was due to changes in the cleavability of the F protein. However, pathogenicity was further increased with passage in chicken brain, following a change in the cleavability of the $\mathrm{F}$ protein [25]. Genetic comparisons between 415/91 and 9a5b demonstrated three amino acid substitutions (128P to H, 495E to $\mathrm{K}, 573 \mathrm{E}$ to Stop codon) in the HN proteins (GenBank accession number: AB524405 and AB524406). Two of these substitutions were detected between $9 \mathrm{a} 3 \mathrm{~b}$ and $9 \mathrm{a} 5 \mathrm{~b}$ and no amino acid substitution in other proteins, thus suggesting that these amino acids are related to the pathogenicity of NDV in chickens (GenBank accession number: AB534205). In the present study, the function of $\mathrm{HN}$ protein and its contribution to virulence were examined by in vitro functional assays using mutant $\mathrm{HN}$ proteins. 


\section{MATERIALS AND METHODS}

Cells and viruses: Human embryonic kidney (HEK)-293 cells were grown in Dulbecco's modified Eagle's medium supplemented with $10 \%$ fetal calf serum. Baby hamster kidney (BHK)-21 cells were grown in Eagle's minimal essential medium (MEM) supplemented with $10 \%$ fetal calf serum. Virus-infected cells were maintained in MEM containing $0.3 \%$ bovine serum albumin. The NDV strains used in this study were Goose/Alaska/415/91 (415/91), and viruses passaged through air sacs and brains; $2 \mathrm{a}, 9 \mathrm{a} 3 \mathrm{~b}, 9 \mathrm{a} 4 \mathrm{~b}$ and $9 \mathrm{a} 5 \mathrm{~b}$ [25]. Viruses were propagated in the allantoic cavity of 10-day-old embryonated chicken eggs for $48 \mathrm{hr}$ at $35^{\circ} \mathrm{C}$, and the allantoic fluid was harvested and stored at $-80^{\circ} \mathrm{C}$.

Cloning of HN and F genes: In order to clone the HN and F genes, two primer sets, HN:415HNstart-EcoRI (5'GAATTCGCCGCCACCATGGAGAGAGGGTCAGCCAAGTTG-3') and 415HNstop-XhoI (5'-CTCGAGCGGAGCTCGCCATGCCTACC-3'), F:415Fstart-BglII (5'AGATCTGCCGCCACCATGGATCCCAAGCCTTCTACCAG-3') and NDHR1 (5'-GGCCTCTTCGACCGTTCTACCCGT-3'), were used for PCR with KOD Plus DNA polymerase (TOYOBO, Tokyo, Japan). The amplified DNA fragments were cloned into pT7Blue using Perfectly Blunt Cloning Kits (Novagen, Darmstadt, Germany). Plasmids were digested with restriction enzyme and cloned in pCAGGS/MCS. The obtained clones were designated pC415HN, pC2aHN, pC9a3bHN, pC9a5bHN and pC9a5bF. pC9a4bHN was constructed from pC9a3bHN using the QuickChange Site-Directed Mutagenesis Kit (Stratagene, La Jolla, CA, U.S.A.).

Construction of mutant HN genes: Mutant HN proteins were also generated by introducing mutations using the QuickChange Site-Directed Mutagenesis Kit (Stratagene). The three amino acid residues at positions 128, 495 and 573 in the mutated $\mathrm{HN}$ proteins were as follows: clone $415-$ $128 \mathrm{H}(128 \mathrm{H}, 495 \mathrm{E}, 573 \mathrm{E})$, clone $415-495 \mathrm{~K}$ (128P, 495K, 573E), clone 9a5b-128P (128P, 495K, 573Stop), clone 9a5b-573E (128H, 495K, 573E). The mutant HN clones in the pT7Blue plasmid were subcloned into pCAGGS and the obtained mutants were designated pC415-128H, pC415495K, pC9a5b-128P and pC9a5b-573E, respectively (Table $1)$. Sequence analysis showed no unexpected mutations in those plasmids

Transient expression systems: Mutated $\mathrm{HN}$ and F proteins were expressed in HEK-293 or BHK-21 cells. All experiments were carried out in 6-well plates seeded a day earlier at $2.0 \times 10^{5}$ cells $/ \mathrm{cm}^{2}$. Plasmids $\left(0.5 \mu \mathrm{g} / \mathrm{cm}^{2}\right)$ were transfected into cells using the TransIT LT1 kit (Panvera, Madison, WI, U.S.A.) according to the manufacturer's protocol. Assays were performed at 48 or $50 \mathrm{hr}$ post-transfection.

Enzyme-linked immunosorbent assay for measurement of cell-expression level of HN proteins: Enzyme-linked immunosorbent assay (ELISA) was performed in order to determine expression levels of HN proteins. Cells expressing $\mathrm{HN}$ proteins were fixed overnight in formalin at $4^{\circ} \mathrm{C}$, and
Table 1. Amino acid residues coded in the constructed $\mathrm{HN}$ expression plasmids

\begin{tabular}{lccc}
\hline \multirow{2}{*}{ Plasmid } & \multicolumn{3}{c}{ Amino acid residues } \\
\cline { 2 - 4 } & $128^{\mathrm{a}}$ & 495 & 573 \\
\hline pC415HN & $\mathrm{P}$ & $\mathrm{E}$ & $\mathrm{E}$ \\
pC2aHN & $\mathrm{P}$ & $\mathrm{E}$ & Stop \\
pC9a3bHN & $\mathrm{P}$ & $\mathrm{E}$ & Stop \\
pC9a4bHN & $\mathrm{H}$ & $\mathrm{E}$ & Stop \\
pC9a5bHN & $\mathrm{H}$ & $\mathrm{K}$ & Stop \\
pC415-128H & $\mathrm{H}$ & $\mathrm{E}$ & $\mathrm{E}$ \\
pC415-495K & $\mathrm{P}$ & $\mathrm{K}$ & $\mathrm{E}$ \\
pC9a5b-128P & $\mathrm{P}$ & $\mathrm{K}$ & Stop \\
pC9a5b-573E & $\mathrm{H}$ & $\mathrm{K}$ & $\mathrm{E}$ \\
\hline
\end{tabular}

a) Amino acid position.

were then washed three times with phosphate-buffered saline (PBS), containing $\mathrm{CaCl}_{2}$ and $\mathrm{MgCl}_{2}$. Subsequently, cells were incubated in $\mathrm{PBS}$ containing $1 \%$ bovine serum albumin at room temperature for $1 \mathrm{hr}$, followed by antiGoose/Alaska/415/91 chicken serum as a primary antibody for $1 \mathrm{hr}$ at room temperature. After washing three times with PBS, goat anti-chicken immunoglobulin G labeled with horseradish peroxidase as a secondary antibody was added for $1 \mathrm{hr}$ at room temperature. After washing three times, the enzyme reaction with $150 \mu l$ of ABTS solution (Roche Diagnostics, Tokyo, Japan) was carried out for 5 min at room temperature. Cell contents were then collected and centrifuged at $8,000 \times g$ for $1 \mathrm{~min}$ and $100-\mu l$ aliquots of supernatant were added to the wells of a 96-well plate. Absorbance was measured with a Model 3550 microplate reader (BIO-RAD, Tokyo, Japan) at a wavelength of 450 nm.

Sequencing: Viral RNA was extracted directly from infected allantoic fluid using the QIAamp Viral RNA Minikit (Qiagen, Tokyo, Japan), and reverse transcription was carried out with M-MLV reverse transcriptase (TaKaRa, Otsu, Japan) using random 6-mers, and cDNA was amplified by PCR. Nucleotide sequences were analyzed using an autosequencer (Gene Rapid, Amersham Pharmacia Biotech, Uppsala, Sweden).

NA assay: NA assay was carried out as described previously [3, 18]. HEK-293 cells transfected with HN protein expression plasmids were washed twice in phosphate-buffered saline and once in phosphate buffer (PB, pH 5.9). The reaction was initiated by the addition of $170 \mu$ of substrate $\operatorname{mix}[12.5 \mathrm{mg} / \mathrm{m} l$ fetuin in $\mathrm{PB}]$ per well. After incubation for $30 \mathrm{~min}$ at $37^{\circ} \mathrm{C}$, the reaction mixture was harvested and centrifuged at $15,000 \times g$ for $1 \mathrm{~min}$, and $100 \mu l$ of supernatant was incubated with $50 \mu l$ of $200 \mathrm{mM}$ sodium periodate for $20 \mathrm{~min}$ at $20^{\circ} \mathrm{C}$. After excess periodate was blocked with $500 \mu l$ of $\mathrm{NaAsO}_{2}$ solution $\left[100 \mathrm{mg} / \mathrm{ml} \mathrm{NaAsO}_{2}, 500 \mathrm{mM}\right.$ $\left.\mathrm{Na}_{2} \mathrm{SO}_{4}, 0.3 \% \mathrm{H}_{2} \mathrm{SO}_{4}\right], 1.25 \mathrm{ml}$ of TBA solution $[6 \mathrm{mg} / \mathrm{m} \mathrm{l} 2$ thiobarbituric acid, $500 \mathrm{mM} \mathrm{Na} \mathrm{SO}_{4}$ ] was added, followed by incubation for $15 \mathrm{~min}$ at $100^{\circ} \mathrm{C}$. Specific pigment was extracted into $2 \mathrm{~m} l$ of acid butanol and the optical density at $549 \mathrm{~nm}$ was measured by photospectrometry. 


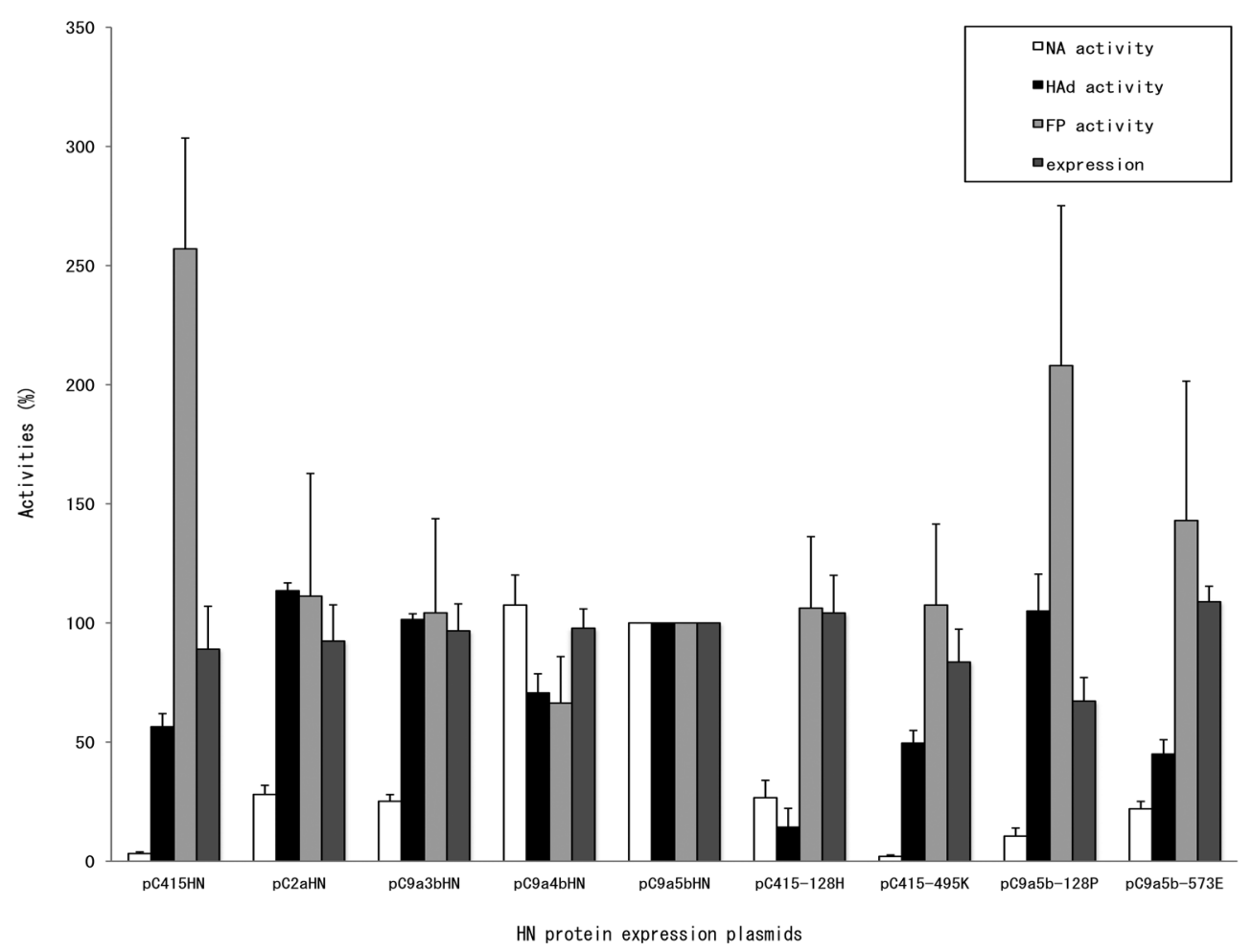

Fig. 1. Functional assays of mutant HN proteins. HAd activity was determined by the ability of expressed HN proteins to absorb chicken erythrocytes. NA activity was determined by the ability of expressed proteins to catalyze the release of sialic acid from fetuin. The ability to complement $9 \mathrm{a} 5 \mathrm{~b} \mathrm{~F}$ in the promotion of fusion was determined by calculating as the ratio of the total number of nuclei in multinuclear cells to the total number of nuclei in the field. The expression levels of HN proteins were determined by ELISA. All data are expressed relative to the amount for the velogenic $9 \mathrm{a} 5 \mathrm{~b}$ protein and represent the mean of at least four independent determinations.

Hemadsorption (HAd) assay: HEK-293 cells transfected with each $\mathrm{HN}$ protein expression plasmid were washed three times in PBS, and were overlaid with $0.75 \%$ chicken erythrocytes (RBCs) in PBS. Plates were kept at $4^{\circ} \mathrm{C}$ for $15 \mathrm{~min}$. Unbound RBCs were removed by washing with PBS three times. The RBCs bound to HN-expressing cells were lysed with $0.05 \mathrm{M}$ ammonium chloride, and the released hemoglobin was measured at $549 \mathrm{~nm}$ in a spectrophotometer.

Fusion promotion (FP) assay: BHK-21 cells transfected with each $\mathrm{HN}$ protein and $\mathrm{F}$ protein plasmids were washed three times with PBS, fixed with cold methanol for $1 \mathrm{hr}$, and stained with Giemsa. The FP index was calculated as the ratio of total nuclei to the number of cells in which nuclei were present [9].

\section{RESULTS}

In order to clarify the contribution of $\mathrm{HN}$ protein to the pathogenicity of NDV, HN proteins from a series of passaged viruses, 415/91, 2a, 9a3b, 9a4b and 9a5b, as well as several mutant proteins, were expressed in cell cultures (Table 1). Expression levels of each mutated $\mathrm{HN}$ protein were comparable to those of the $415 / 91 \mathrm{HN}$ protein. The cells expressing each mutant $\mathrm{HN}$ protein were assayed for NA, HAd and FP activities in order to explore the effects of amino acid substitutions.

The NA activity of the $415 / 91 \mathrm{HN}$ protein was only $3 \%$ that of the $9 \mathrm{a} 5 \mathrm{~b}$ HN protein. The $2 \mathrm{a} \mathrm{HN}$ protein had the E573stop substitution, and the 9a3b HN protein had 25$28 \%$ NA activity when compared to $9 a 5 b$. Furthermore, the 9a4b HN protein, which had the $\mathrm{P} 128 \mathrm{H}$ substitution, showed a conspicuous increase in NA activity, and reached a similar titer to that of the $9 \mathrm{a} 5 \mathrm{~b}$. The NA activity of the mutant HN 415-128H protein was about 7-fold higher than that of 415, and that of mutant HN 9a5b-128P and 415$495 \mathrm{~K}$ proteins showed similar activity to that of the 415 . The mutant HN 9a5b-573E protein showed $60 \%$ lower NA activity than $9 \mathrm{a} 5 \mathrm{~b}$ (Fig. 1). These results indicate that two amino acid substitutions, $128 \mathrm{P}$ to $\mathrm{H}$ and 573E to Stop, markedly increase NA activity.

The HAd activity of the $415 / 91 \mathrm{HN}$ protein was $56 \%$ that of the $9 \mathrm{a} 5 \mathrm{~b}$ HN protein. However, the HAd activity of the $2 \mathrm{a}$ and $9 \mathrm{a} 3 \mathrm{~b} \mathrm{HN}$ proteins were similar to that of $9 \mathrm{a} 5 \mathrm{~b}(102-$ $114 \%$ ), although 9a4b showed lower (71\%) activity. More- 
over, the HAd activity of the mutant HN proteins also indicated that the amino acid substitution of $573 \mathrm{E}$ to a stop codon is important for HAd activity (Fig. 1).

The FP activity of the $415 / 91 \mathrm{HN}$ protein was higher than that of $9 \mathrm{a} 5 \mathrm{~b}$ (by approximately $250 \%$ ). The FP activities of the $2 \mathrm{a}$ and $9 \mathrm{a} 3 \mathrm{~b} H \mathrm{HN}$ proteins were similar to those of the $9 \mathrm{a} 5 \mathrm{~b}$, and $9 \mathrm{a} 4 \mathrm{~b}$ HN protein was lower $(65 \%)$. The activities of mutant $\mathrm{HN} 415-495 \mathrm{~K}$ protein and $415-128 \mathrm{H}$ protein were almost equal to that of $9 \mathrm{a} 5 \mathrm{~b} \mathrm{HN}$ protein. Moreover, the mutant HN 9a5b-128P protein and 9a5b-573stop protein also had high FP activities (Fig. 1). There was no correlation between FP activity and amino acid substitutions.

\section{DISCUSSION}

In this report, we examined the functional role of the $\mathrm{HN}$ protein of NDV in virulence. The HN protein of NDV is a multifunctional protein and has NA, HAd and FP activities $[10,11,27]$. Therefore, we examined the effects of three amino acid substitutions (128P to H, 495E to K, and 573E to stop codon) introduced into the HN protein of $9 \mathrm{a} 5 \mathrm{~b}$ on these biological activities. The results showed that the $128 \mathrm{H}$ substitution markedly increases NA activity. The residue at amino acid 128 is distant from the NA catalytic site [4]; thus, substitution of this residue may alter the conformation of HN protein and affect NA activity.

Based on differences in stop codon position, NDV HN proteins are classified into three types, with 616,577 or 571 amino acids [23]. The largest type, with 616 amino acids, is the precursor-type, designated $\mathrm{HN}_{0} 616$, and is proteolytically converted into the biologically active HN protein [19]. Almost all lentogenic waterfowl isolates contain this type of precursor $\mathrm{HN}_{0}$. The translation products with 577 and 571 amino acids are already in an active form, and are designated HN577 and HN571, respectively. Velogenic strains contain these active $\mathrm{HN}$ proteins. In the present study, it was found that the original lentogenic waterfowl isolate $415 / 91$ contains the precursor-type $\mathrm{HN}_{0} 616$, and the chicken-passaged virus 2 a converts this to an active HN protein of 572 amino acids. These results demonstrate that the prototype $\mathrm{HN}_{0} 616$ protein from waterfowl isolates is converted to active $\mathrm{HN}$ by a point mutation to change the position of the stop codon (573E to stop codon) during passage in chickens. Furthermore, such mutations may occur at the earlier stage of passaging when compared to F cleavage site changes in nature. The fact that there are no field isolates containing highly cleavable $\mathrm{F}$ and precursor $\mathrm{HN}_{0}$ support this notion [28].

On the other hand, the $495 \mathrm{~K}$ substitution had little effect on any activities. Takimoto et al. [27] reported that the FP activity a mutant HN protein of NDV, with a Glu to Ala change at residue 495 , was lower when compared to the wild-type $\mathrm{HN}$ protein. The residue at 495 is distant from the site of interaction between the $\mathrm{F}$ protein and the receptor binding site. The functional significance of the $495 \mathrm{~K}$ substitution thus requires further investigation.

The NA activity of $9 \mathrm{a} 5 \mathrm{~b} \mathrm{HN}$ protein was much higher than that of $9 \mathrm{a} 3 \mathrm{~b}$, while the HAd and FP activities were comparable. As the pathogenicity of $9 \mathrm{a} 5 \mathrm{~b}$ was higher than that of 9a3b, this change in NA activity was thought to affect its pathogenicity in chickens. The pathogenicity of $9 \mathrm{a} 4 \mathrm{~b}$ was not determined because $9 \mathrm{a} 4 \mathrm{~b}$ appears to include a mixed population and the IVPI values were uncertain. Further investigation using cloned $9 \mathrm{a} 4 \mathrm{~b}$ virus is necessary for comparative analysis of pathogenicity.

The role of the HN gene in NDV virulence has been reported [8]. Through the use of reverse genetics procedures, the HN genes of virulent and avirulent recombinant NDV strains were exchanged. The chimeric viruses with reciprocal $\mathrm{HN}$ proteins either gained or lost virulence, indicating that virulence is associated with the amino acid differences in the HN protein. The present study demonstrated that a single amino acid substitution (128P to $\mathrm{H}$ ) in the $\mathrm{HN}$ protein has an affect on the NA activity and is possibly correlated with the virulence. These findings support the hypothesis that development of virulence in NDV is a multigenic event. However, the exact mechanism responsible for the effects of NA activity on virulence is still unknown. Further studies using reverse genetics technique are therefore necessary to clarify this issue.

\section{REFERENCES}

1. Alexander, D. J. 1988. Newcastle disease diagnosis. pp. 147160. In: Newcastle Disease (Alexander, D. J. ed.), Kluwer Academic Publishers, Boston.

2. Alexander, D. J. 2000. Newcastle disease and other avian paramyxoviruses. Rev. Sci. Tech. 19: 443-462.

3. Aymard-Henry, M., Coleman, T. M., Dowdle, R. W. and Laver, G. W. 1973. Influenza virus neuraminidase and neuraminidase-inhibition test procedures. Bull. WHO 48: 199202.

4. Crrennell, S., Takimoto, T., Portner, A. and Taylor, G. 2000. Crystal structure of the multifunctional paramyxovirus hemagglutinin-neuraminidase. Nat. Struct. Biol. 7: 1068-1074.

5. Garten, W., Berk, W., Nsgsi, Y., Rott, R. and Klenk, D. H. 1980. Mutational changes of the protease susceptibility of glycoprotein F of Newcastle disease virus: effects on pathogenicity. J. Gen. Virol. 50: 135-147.

6. Gravel, K. A. and Morrison, T. G. 2003. Interacting domains of the $\mathrm{HN}$ and F proteins of Newcatle disease virus. J. Virol. 77: 11040-11049.

7. Huang, Z., Krishnamurthy, S., Panda, A. and Samal, S. K. 2003. Newcastle disease virus V protein is associated with viral pathogenesis and functions as an alpha interferon antagonist. J. Gen. Virol. 77: 8676-8685.

8. Huang, Z., Panda, A., Elankumaran, S., Govindarajan, D., Rockemann, D. D. and Samal, S. K. 2004. The hemagglutininneuraminidase protein of Newcastle disease virus determines tropism and virulence. J. Virol. 78: 4176-4184.

9. Kohn, A. 1965. Polykaryocytosis induced by Newcastle disease virus in monolayers of animal cells. Virology 26: 228245.

10. Lamb, R. A. 1993. Paramyxovirus fusion: a hypothesis for changes. Virology 197: 1-11.

11. Lamb, R. A. and Kolakofsky, D. 2001. Paramyxoviridae: the virus and their replication. pp. 1305-1340. In: Fields Virology 
(Knipe, D. M. and Howley, P. M. eds.), Lippincott Williams and Wilkins, Philadelphia.

12. Leeuw, D. O. S. and Peeters, B. 1999. Complete nucleotide sequence of Newcastle disease virus: evidence for the existence of a new genus within the subfamily Paramyxovirinae. $J$. Gen. Virol. 80: 131-136.

13. Leeuw, D. O. S., Hartog, L., Koch, G. and Peeters, B. P. H. 2003. Effect of fusion cleavage site mutations on Virulence of Newcastle disease virus: non-virulent cleavage site mutants revert to virulence after one passage in chicken brain. J. Gen. Virol. 84: 475-484.

14. Leeuw, D. O. S., Koch, G., Hartog, L., Ravenshorst, N. and Peeters, B. P. H. 2005. Virulence of Newcastle disease virus is determined by the cleavage site of the fusion protein and by both the stem region and globular head of the haemagglutininneuraminidase protein. J. Gen. Virol. 86: 1759-1769.

15. Man-Seong, P., Adolfo, S. G., Jerome, C. F., Christopher, B. F. and Peter, P. 2003. Newcastle disease virus V protein is a determinant of host range restriction. J. Virol. 77: 9522-9532.

16. Mayo, M. A. 2002. A summary of taxonomic changes recently approved by ICTV. Arch. Virol. 147: 1655-1656.

17. Mitnaul, L. J., Matrosovich, M. N., Castrucci, M. R., Tuzikov, A. B., Bovin, N. V., Kobasa, D. and Kawaoka, Y. 2000. Balanced hemagglutinin and neuraminidase activities are critical for replication of influenza Avirus. J. Virol. 74: 6015-6020.

18. Morrison, T. G. and McGinnes, L. W. 1989. Avian cells expressing the Newcastle disease virus HN protein are resistant to NDV infection. Virology 171: 10-17.

19. Nagai, Y. and Klenk, H. D. 1977. Activation of precursors to both glycoporteins of Newcastle disease virus by proteolytic cleavage. Virology 77: 125-134.

20. Nagai, Y., Klenk, H. and Rott, R. 1976. Proteolytic cleave of the viral glycoproteins and its significance for the virulence of NDV. Virology 72: 494-508.
21. Ogasawara, T., Gotoh, B., Suzuki, H., Asaka, J., Shimokata, K., Rott, R. and Nagai, Y. 1992. Expression of factor X and its significance for the determination of paramyxovirus tropism in the chick embryo. EMBO J. 11: 467-472.

22. Rott, R. and Klenk, H. D. 1988. Molecular basis of infectivity and pathogenicity of Newcastle disease virus. pp. 98-112. In: Newcastle Disease (Alexander, D. J. ed.), Kluwer Academic Publishers, Boston.

23. Sakaguchi, T., Toyoda, T., Gotoh, B., Inocencio, N. M., Kuma, K., Miyata, T. and Nagai, Y. 1989. Newcastle disease virus evolution. I. Multiple lineages defined by sequence variability of the hemagglutinin-neuraminidase gene. Virology 169: 260272.

24. Seal, B. S., King, J. D. and Meinersmann, J. R. 2000. Molecular evolution of the Newcastle disease virus matrix protein gene and phylogenetic relationships among the paramyxoviridae. Virus Res. 66: 1-11.

25. Shengqing, Y., Kishida, N., Ito, H., Kida, H., Otsuki, K., Kawaoka, Y. and Ito, T. 2002. Generation of velogenic Newcastle disease viruses from a nonpathogenic waterfowl isolate by passaging in chickens. Virology 301: 206-211.

26. Takakuwa, H., Ito, T., Takeda, A., Okazaki, K. and Kida, H. 1998. Potential virulent Newcastle disease viruses are maintained in migratory waterfowl populations. Jpn. J. Vet. Res. 45: 207-215.

27. Takimoto, T., Taylor, L. G., Connaris, C. H., Crennell, J. S. and Portner, A. 2002. Role of the hemagglutinin-neuraminidase protein in the mechanism of paramyxovirus-cell membrane fusion. J. Virol. 76: 13028-13033.

28. Toyoda, T., Sakaguchi, T., Hirota, H., Gotoh, B., Kuma, K., Miyata, T. and Nagai, Y. 1989. Newcastle disease virus evolution. II. Lack of gene recombination in generating virulent and avirulent strains. Virology 169: 273-282. 